\title{
PHYSICAL SEISMIC VULNERABILITY ASSESSMENT OF TEHRAN USING THE INTEGRATION OF GRANULAR COMPUTING AND INTERVAL DEMPSTER- SHAFER
}

\author{
M.R. Delavar ${ }^{\mathrm{a}}$, M.Bahrami $^{\mathrm{b}}$ and M.Zare ${ }^{\mathrm{c}, \mathrm{a}}$ \\ ${ }^{a}$ Center of Excellence in Geomatic Eng. in Disaster Management, School of Surveying and Geospatial Eng., College of Eng., \\ University of Tehran, Tehran, Iran, mdelavar@ut.ac.ir \\ ${ }^{\mathrm{b}}$ MSc. Student, GIS Dept., School of Surveying and Geospatial Eng., College of Eng., University of Tehran, Tehran, Iran, \\ m.bahrami70@ut.ac.ir \\ ${ }^{\mathrm{c}}$ International Institute of Seismology and Earthquake Engineering, Tehran, Iran, mzare@iiees.ac.ir
}

\section{Commission IV, WG IV/3}

KEY WORDS: Uncertainty, Granular Computing, Interval Mathematics, Interval Dempster-Shafer, Physical Seismic Vulnerability Assessment, Multi Criteria Decision Making

\begin{abstract}
:
Several faults exist in the vicinity of Tehran, the capital of Iran such as North Tehran, Ray, Mosha and Kahrizak. One way to assist reducing the damage caused by the earthquake is the production of a seismic vulnerability map. The study area in this research is Tehran, based on the assumption of the activation of North Tehran fault. Degree of Physical seismic vulnerability caused by the earthquake depends on a number of criteria. In this study the intensity of the earthquake, land slope, numbers of buildings' floors as well as their materials are considered as the effective parameters. Hence, the production of the seismic vulnerability map is a multi criteria issue. In this problem, the main source of uncertainty is related to the experts' opinions regarding the seismic vulnerability of Tehran statistical units. The main objectives of this study are to exploit opinions of the experts, undertaking interval computation and interval Dempster-Shafer combination rule to reduce the uncertainty in the opinions of the experts and customizing granular computing to extract the rules and to produce Tehran physical seismic vulnerability map with a higher confidence. Among 3174 statistical units of Tehran, 150 units were randomly selected and using interval computation, their physical vulnerabilities were determined by the experts in earthquake-related fields. After the fusion of the experts' opinions using interval Dempster-Shafer, the information table is prepared as the input to granular computing and then rules are extracted with minimum inconsistency. Finally, the seismic physical vulnerability map of Tehran was produced with $\% 72$ accuracy.
\end{abstract}

\section{INTRODUCTION}

Urban areas are threatened by natural disasters such as hurricanes and earthquakes in some parts of the world. Earthquake is one of the most devastating natural disasters in Iran (Aghamohhamdi et al., 2013). Tehran mega city is not only vulnerable to earthquakes, but also is awaited a huge earthquake with a magnitude greater than 6 in Richter scale for many years. Based on the statistical studies on earthquakes that have been recorded in the area of Tehran and Ray, on average every 158 years a devastating earthquake with a magnitude of around 6 and above on the Richter scale has been occurred in the area. The main cause of earthquakes in Tehran is the existence of faults such as Northern Tehran, Ray, Mosha, and Kahrizak in the Tehran Metropolitan Area (TMA) (JICA, 2000). In addition, high population, rapid urban expansion, and the existence of some non-standard buildings, have made Tehran vulnerable to earthquakes (Samadi Alinia and Delavar, 2011, Hashemi and Alesheikh, 2012). This seismic vulnerability may result in great human and financial losses. One of the methods for reducing the risks caused by earthquakes is seismic vulnerability mapping. Since a number of factors are involved in determining the seismic vulnerability, this problem has been associated with uncertainties.

Mismanagement of these sources of uncertainties will lead to unreliable results. Several studies have been already conducted in this field including the project of Japan International Cooperation Agency (JICA) which is among the first studies to evaluate the seismic vulnerability of Tehran (JICA, 2000). Aghataher et al. (2005) have investigated human vulnerability

in Tehran using fuzzy logic and analytical hierarchy process. Silavi et al. (2006) have used intuitionistic fuzzy set theory in order to manage the uncertainty in seismic vulnerability evaluation. Amiri et al. $(2007,2008)$ have handled the uncertainty in physical and human seismic vulnerability of Tehran by the means of rough sets theory and Dempster-Shafer evidence theory. Samadi Alinia et al. (2010) have also studied seismic vulnerability of Tehran using granular computing (GrC). Khamespanah et al. (2016) have investigated Tehran physical seismic vulnerability using the integration of granular computing and rough set theory. Sheikhian et al. (2017) have studied Tehran seismic vulnerability using a neural network and granular computing integrated model. Moradi et al. (2016) have developed an integrated model of Choquet integral and game theory for Tehran physical vulnerability assessment.

Each of the mentioned approaches handles a different aspect of the uncertainty existing in the problem. The main objective of this paper is to handle the uncertainty associated with the conflicts in the expert's opinions in allocation of physical seismic vulnerability of statistical units in Tehran via a combination of granular computing model and Interval Dempster-Shafer. In this study, opinions of multiple experts are used to assess the vulnerability of the statistical units where the 
experts' opinions are in the form of some intervals. In order to eliminate inconsistencies and uncertainties in the experts' opinions, Interval Dempster-Shafer combination rule (Lee and formed with minimum amount of inconsistency. In the previous related studies (Samadi Alinia and Delavar, 2011, Khamespanah et al., 2016), experts' opinions were in the form of deterministic values, however, in this research, interval values have been used to reduce the uncertainty. The study area in this research is statistical units of Tehran. Moreover, it is assumed that North Tehran fault is the only fault activated among the mentioned ones and the vulnerability of the buildings of each statistical unit is taken as the degree of vulnerability of that unit.

The remainder of this paper is as follows. Section 2 describes granular computing theory. In Section 3, Interval computation is discussed. Dempster-Shafer theory is discussed in Section 4. The methodology is explained in Section 5. The concluding remarks are given in Section 6.

\section{GRANULAR COMPUTING}

$\mathrm{GrC}$ is a deductive approach to knowledge discovery, in which granules of information provide a concept of encapsulating similar objects (Zadeh and Kacprzyk, 1999). GrC approach has applications in the fields of image processing, pattern recognition, machine learning, and so on. Imprecise, vagueness and uncertainty of the information contained in granular computing, is one of its features (Pedrycz et al., 2008). GrC is related to data mining in terms of forming concepts and recognizing their relationships. Each concept is a unit of opinions that consists of two parts called extension and intension. In granular computing, each granule is interpreted as an instance of the concept and the features which are used to describe the granule are called intension. Extension is the set of the objects that are used in forming the concept. Relations between the concepts are expressed as rules and appropriate rules may be extracted by some measurements. GrC based on information table mainly involves decomposing the universe set on the basis of indicators describing the objects. Granule decomposition is a process in which larger granules are divided up into smaller ones, as a top-down process (Yao, 2007). Information table is defined by Equation (1) (Pawlak, 1982, Yao and Zhong, 2002) :

$\mathrm{S}=(\mathrm{U}, \mathrm{At}, \mathrm{L},\{\mathrm{Va} \mid \mathrm{a} \in \mathrm{At}\},\{\mathrm{Ia} \mid \mathrm{a} \in \mathrm{At}\})$

Where:

$\mathrm{U}$ : a finite non-empty set of objects

At : a finite non-empty set of attributes

$\mathrm{L}:$ a language defined by using attributes in $A_{t}$

$V_{a}:$ a non-empty set of values of $a \in A t$

$I_{a}: U \rightarrow V_{a}$ is an information function mapping an object from

$U$ to exactly one possible value of attribute $a$ in $V a$.

Granular computing strategy is granule-based, that is, each granule is formed by attribute-value pairs and instead of choosing a suitable partitioning, the focus is on choosing a single granule (Samadi Alinia and Delavar, 2011).
Zhu, 1992) has been used. After the fusion of the experts' opinions, information table of granular computing data is

In data mining, typically the rules are interpreted as probabilities, and different measurements are defined to reflect various aspects of the rules (Zhong et al., 2003). A rule can be expressed in the form of $\phi \Rightarrow \Psi$, where $\phi$ and $\Psi$ are intensions of the two concepts (Gupta et al., 1979, Zhong et al. 2003). The measurements used in this study are as follows:

\subsection{Generality}

Generality determines the relative size of a granule. This measurement is defined as the ratio of granule size to the size of the universe set presented in Equation (2) (Yao, 2001, Zhong et al., 2003) :

$\mathrm{G}(\phi)=\frac{|m()|}{|U|} \quad 0 \leq \mathrm{G}(\phi) \leq 1$

\subsection{Absolute support}

For the two given concepts $\Phi$ and $\Psi$, the absolute support (AS) or confidence that $\Phi$ provides to the $\Psi$, is defined by Equation (3) (Yao and Zhong, 2002).

$\operatorname{AS}(\phi \Rightarrow \psi)=\operatorname{AS}(\psi \mid \phi)=\frac{|\mathrm{m}() \mathrm{m}()|}{|\mathrm{m}()|} \quad 0 \leq \mathrm{AS}(\psi \mid \phi) \leq 1$

\subsection{Coverage}

The coverage of concept $\Phi$ provided by concept $\psi$ is defined by Equation (4) (Yao, 2001):

$\mathrm{CV}(\phi \Rightarrow \psi)=\frac{|\mathrm{m}() \mathrm{m}()|}{|\mathrm{m}()|}$

This quantity displays the conditional probability of a randomly selected object to satisfy $\phi$, when satisfies $\psi$ and shows the coverage of $\psi$ upon $\phi$ (Yao, 2001, 2008).

\subsection{Conditional Entropy}

By considering a family formulas of $\psi=\left\{\psi_{1}, \psi_{2}, \ldots, \psi_{n}\right\}$ which induces a partition $\pi(\psi)=\left\{\mathrm{m}\left(\psi_{1}\right), \ldots, \mathrm{m}\left(\psi_{\mathrm{n}}\right)\right\}$ of the universe, for formulas $\phi$, the conditional entropy, $\mathrm{H}(\psi \mid \phi)$, that reveals the uncertainty of formulas $\phi$ based on formulas $\psi$, is defined by Equation (5) (Yao, 2008):

$\mathrm{H}(\psi \mid \phi)=-\sum_{\mathrm{i}=1}^{\mathrm{n}} \mathrm{p}(\mathrm{i} \mid) \log (p(i \mid))$

$p(i \mid)=\frac{|\mathrm{m}() \mathrm{m}(\mathrm{i})|}{|\mathrm{m}()|}$

If $\phi$ is a certain formula, $(p(i \mid)=1$ and $p(j \mid)=0 \quad \forall \mathrm{j} \in 1: \mathrm{n}$ and $\mathrm{j} \neq \mathrm{i}$ ), entropy reaches the minimum value i.e. 0 .

\subsection{Rules Extraction}

The procedure of extracting rules and their prioritization via granular computing algorithm is illustrated in Figure 1. 


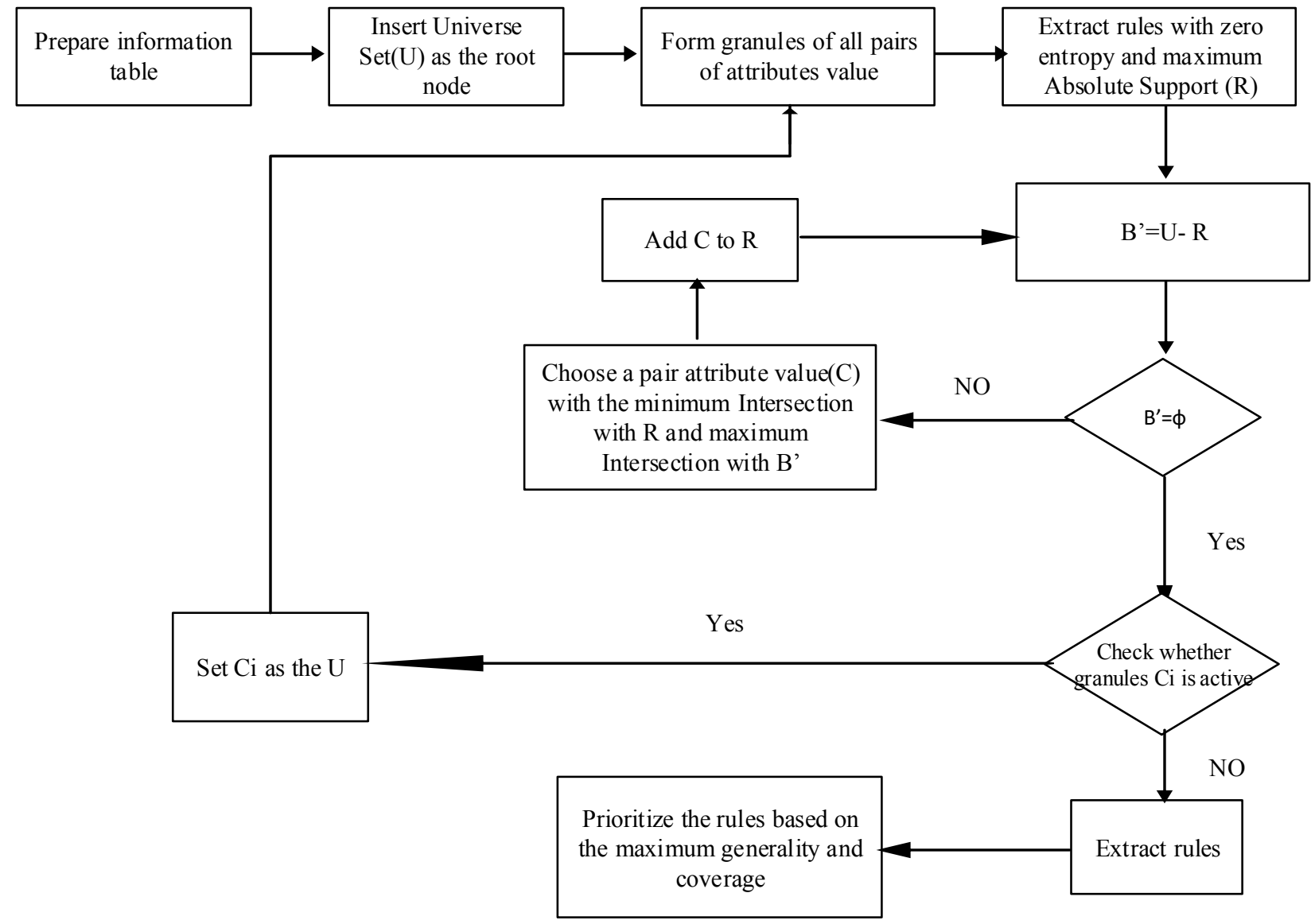

Figure 1. Procedure for extracting rules with granular computing

\section{INTERVAL COMPUTATION}

Interval computation is an important part of granular computing. Sometimes a part of the data is gathered through experts' opinions. Experts' opinions are not absolutely exact due to their limited and conflicted knowledge. Thus, there is an approximation error in their opinions. If the approximation error is determined by a bound, $\Delta I$, it will be guaranteed that the actual amount of the quantity belongs to a granule defined by Equation (6) (Pedrycz et al., 2008):

$$
\mathbf{x}_{\mathbf{i}} \stackrel{\text { def }}{=}[\tilde{x} i-\Delta i, \tilde{x} i+\Delta i]
$$

When the interval of the experts' opinions is large, it will be more probable that the unknown quantity lies in the interval. So experts can use interval computation to handle the uncertainty (Pedrycz et al., 2008).

Interval number is a useful tool to manage the uncertainty caused by human factors in multi-criteria decision problems. For the multi-criteria decision problems in the real world, it is not justified to use just one deterministic value from the experts as the decision class (Dou et al., 2014). Interval analysis is a simple and intuitive method to handle uncertainty of information in complex decision problems. Experts can use interval numbers to express their opinion regarding the problem (Kang et al., 2011)

An interval number such as $\mathrm{X}$ is a set of real numbers defined by Equation (7) (Moore et al., 2009):
$\mathrm{X}=[\underline{\mathrm{X}}, \bar{X}]=\{\mathrm{x} \in \mathbb{R}: \underline{\mathrm{X}} \leq \mathrm{x} \leq \bar{X}\}$

Interval $[\mathrm{x}, \mathrm{x}]$ is equivalent to a real number $\mathrm{x}$. Let $\mathrm{X}=[\underline{\mathrm{X}}, \bar{X}]$ and $\mathrm{Y}=[\underline{Y}, \bar{Y}]$, be two interval numbers. Basic mathematical operations on the intervals are defined by Equations $(8,9,10$, 11, 12) (Moore et al., 2009) :

$\mathrm{X}+\mathrm{Y}=[\underline{\mathrm{X}}+\underline{\mathrm{Y}}, \overline{\mathrm{X}}+\overline{\mathrm{Y}}]$

$\mathrm{X}-\mathrm{Y}=[\mathrm{X}-\overline{\mathrm{Y}}, \overline{\mathrm{X}}-\mathrm{Y}]$

$\mathrm{X} . \mathrm{Y}=[\min \mathrm{S}, \max \mathrm{S}]$,

$\mathrm{S}=\{\underline{\mathrm{X}} \underline{\mathrm{Y}}, \underline{\mathrm{X}} \overline{\mathrm{Y}}, \overline{\mathrm{X}} \underline{\mathrm{Y}}, \overline{\mathrm{X}} \bar{Y}\}$

$\mathrm{X} / \mathrm{Y}=\mathrm{X} .(1 / \mathrm{Y}), \quad 1 / \mathrm{Y}=[1 / \overline{\mathrm{Y}}, 1 / \underline{\mathrm{Y}}], \quad 0 \notin \mathrm{Y}$

Degree of preference is defined as the degree by which an interval is larger than the other one. Degree of preference of a over $\mathrm{b}($ or $\mathrm{a}>\mathrm{b}$ ) is defined by Equation (13) (Wang et al., 2005):

$\mathrm{P}(\mathrm{a}>\mathrm{b})=\frac{\max (0, \mathrm{a} 2-\mathrm{b} 1)-\max (0, \mathrm{a} 1-\mathrm{b} 2)}{(\mathrm{a} 2-\mathrm{a} 1)+(\mathrm{b} 2-\mathrm{b} 1)}$

Degree of preference of $b$ over $a($ or $b>a)$ is defined by Equation (14) (Wang and Elhang., 2006): 
$\mathrm{P}(\mathrm{b}>\mathrm{a})=\frac{\max (0, \mathrm{~b} 2-\mathrm{a} 1)-\max (0, \mathrm{~b} 1-\mathrm{a} 2)}{(\mathrm{a} 2-\mathrm{a} 1)+(\mathrm{b} 2-\mathrm{b} 1)}$

The normalization of interval numbers is usually necessary in the multi-criteria decision problems with uncertainty. If uncertainty exists in the values of some of the criteria, the values will be specified with interval. The normal intervals facilitate computations. Normalization of interval numbers is done based on interval computations, illustrated in Figure (2) (Wang and Elhang, 2006).

\section{INTERVAL DEMPSTER-SHAFER}

Dempster-Shafer Theory (DST) is the mathematical theory of evidence introduced by Dempster (1968) and then it was extended by Shafer (1976). It is a powerful tool for data integration and management of uncertainty (Sentz and Ferson, 2002). An allocation of probability mass is assigned to sets Or intervals in this theory. The significant properties of DST are the capability of combining multiple sources (evidences) and modeling their conflicts (Yager,1992). In Dempster-Shafer Theory, basic probability assignment (BPA) plays a key role. In practical situations, the basic probability assignment is usually provided by experts subjectively.

If $X=\left\{u_{1}, u_{2} \ldots, u_{n}\right\}$ shows a finite set of universe (frame of discernment), for any subset of $X$ such as $\mathrm{A}$, a BPA could be defined As $\mathrm{M}: 2^{\mathrm{X}} \rightarrow[0,1] *[0,1]$ that has the properties defined by Equations $(15,16)$ (Lee and Zhu, 1992):

$$
\mathrm{M}(\Phi)=[0,0]
$$

$$
\sum_{A X} M(A)=[1,1]
$$

Assume M1 and M2 are two evidences, for combination of these evidences Equation (17) is used (Lee and Zhu, 1992):

$\mathrm{M}(\mathrm{C})=\sum_{A B=C} M 1(A) * \mathrm{M} 2(\mathrm{~B})$

After the combination, the experts' points of views in sample areas are combined and each sample is given a unique vulnerability potential.

\section{METHODOLOGY}

In this paper, The study area is Tehran, and physical seismic vulnerability map of the mega city has been produced based on the assumption of the activation of North Tehran fault. The North Tehran fault is $90 \mathrm{Km}$ long located at the southernmost piedmont of Central Alborz. It has an E-W to ENE-WSW strike, a dip of less than $75^{\circ}$ and a thrust mechanism (Berberian and Yeats, 1999). Seismic vulnerability criteria that are considered in this study include topographic slope in percent (slope), intensity of earthquake per unit (MMI), the percentage of poor quality buildings with four floors or less (Buil_Less4), the percentage of poor quality buildings with more than four floors (Buil_more4), the percentage of buildings constructed before 1966 (Bef-66), the percentage of buildings constructed between 1966 and 1988 (Bet-66-88). (Aghataher et al., 2005, Silavi et al., 2006, Amiri et al., 2008, Samadi Alinia and Delavar, 2011, Khamespanah et al., 2016, Moradi et al. 2017 and Sheikhian et al. 2017). Since Iranian regulations for building designs have been approved in 1966, buildings constructed before this date are considered as non-standard constructions. Moreover, fortification regulations against earthquakes were applied for the first time in 1988. In this regard, the percentage of buildings constructed before 1966 and the percentage of buildings constructed between 1966 and 1988 are considered as effective parameters (Khamespanah et al., 2016). Based on these criteria, the data were collected over the Tehran statistical units. The criteria values were classified into four classes with Natural Break method in the ArcGIS software. Among the statistical units, 150 units were randomly selected, then 5 earthquake related experts were asked to determine the degree of vulnerability of each statistical unit with one of the intervals [1 2], [2 3], [3 4], [4 5] where, 1 represents very low vulnerability and 5 represents very high vulnerability. Unlike the previous researches, the vulnerability of each statistical unit is not determined deterministically, but using interval mathematics. The degree of vulnerability of each statistical unit is determined with an interval by the experts. Therefore, the uncertainty in the experts' opinion is reduced using interval mathematics. Then, using interval Dempster-Shafer, the experts' opinions are aggregated. The fusion process is as follows:

1. Normalization of experts' opinions regarding seismic physical vulnerability of the statistical units

2. The use of the combination function of Interval Dempster-Shafer

At the end, vulnerability of each statistical unit is expressed as an interval. Consequently, the data of information table are prepared, which consists of two parts, including the expert opinions data and the vulnerability criteria data, in order to be entered to the granular computing model. As the next step, using information table and granular computing model, the rules are extracted with minimum conflict and are prioritized. By applying the rules to the whole Tehran statistical units, the degree of seismic physical vulnerability of each statistical unit is determined by an interval. The information table for 20 randomly selected statistical units is shown in Table 1.

According to Table 1, granular network for extracting the rules is shown in Figure 3. Tehran seismic physical vulnerability map using the integrated granular computing and interval DST model assuming North Tehran Fault activation is shown in Figure 4.

According to the vulnerability map shown in Figure 4, none of the urban statistical units has vulnerability in [1 2$]$ interval, \%15 of the urban statistical units have vulnerability in [2 3] interval, $\% 37$ of the urban statistical units have vulnerability in [3 4] interval, $\% 47$ of the urban statistical units have vulnerability in [4 5] interval, and $\% 1$ of the urban statistical units have not been classified. In order to verify the agreement of the model, 100 training data and $\mathrm{k} /(\mathrm{k}+\mathrm{n}$ ) formula were used (Zhao and Yao 2005). In this formula, $\mathrm{k}$ is the number of units that were correctly classified and $\mathrm{n}$ is the number of units that have not been classified correctly.

The model agreement to the selected training data was $\% 72$. This model compare with the previous GrC algorithm implemented by Khamespanah et al. (2016), which resulted in $60 \%$ agreement for the North Tehran fault, provided better agreement with the selected training data. 


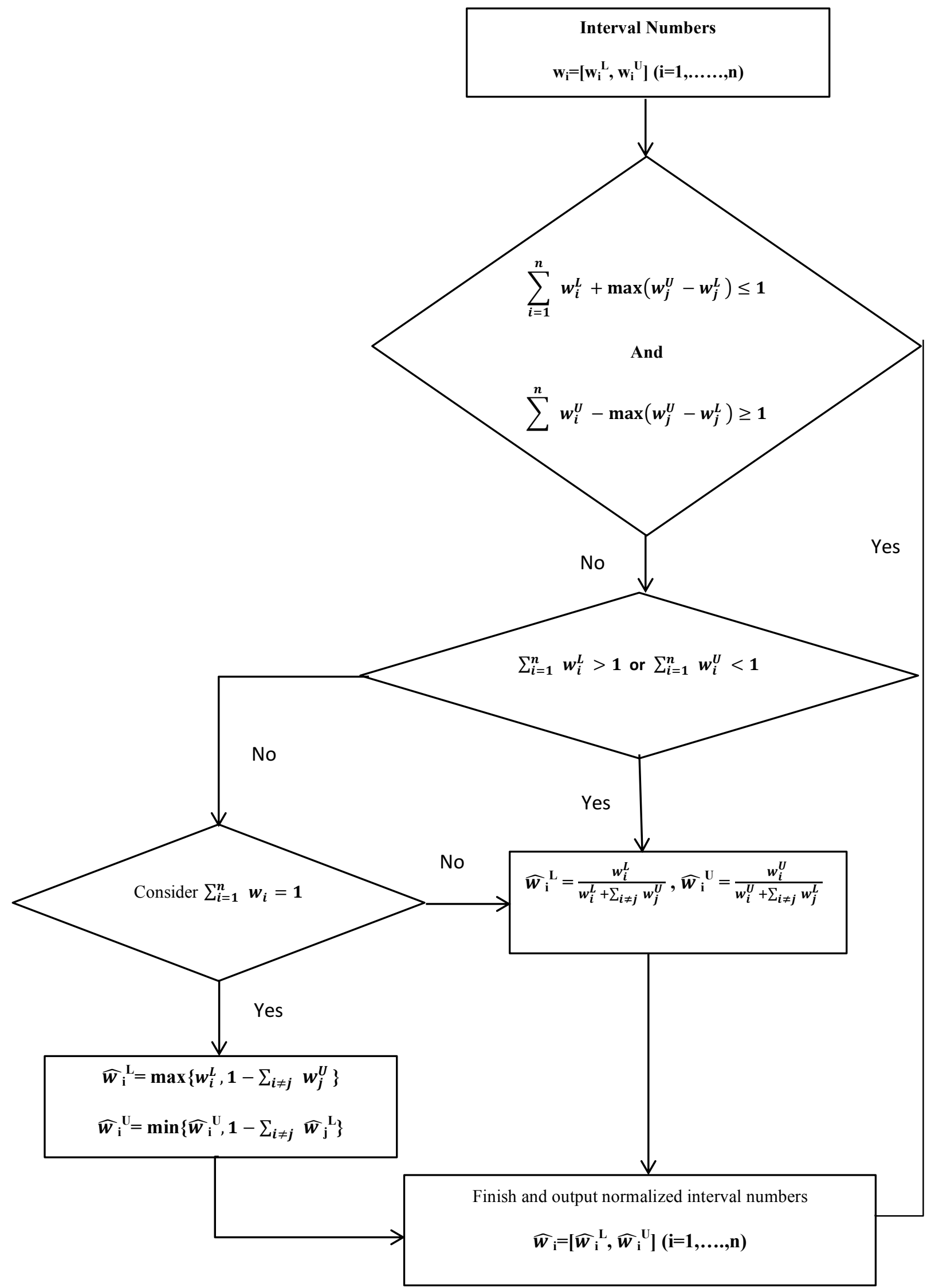

Figure2. Normalization of Interval Numbers (Wang and Elhang., 2006) 


\begin{tabular}{|c|c|c|c|c|c|c|c|c|c|c|c|}
\hline$\underset{\sim_{\mid}}{\Xi_{\mid}}$ & $\frac{\tilde{0}}{\sim}$ & $\sum$ & 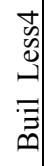 & $\begin{array}{l}0 \\
0 \\
0 \\
\frac{1}{0} \\
\infty\end{array}$ & $\begin{array}{c}\infty \\
\infty \\
1 \\
0 \\
0 \\
1 \\
0 \\
0 \\
\infty\end{array}$ & $\begin{array}{c}\stackrel{ \pm}{0} \\
\vdots \\
\vdots \\
:= \\
:\end{array}$ & $E_{1}$ & $E_{2}$ & $E_{3}$ & $\mathrm{E}_{4}$ & $\mathrm{E}_{5}$ \\
\hline 1 & 4 & \begin{tabular}{|l|}
4 \\
\end{tabular} & 1 & 1 & 2 & 2 & [4 5] & 4 5] & $\left.\begin{array}{lll}3 & 4\end{array}\right]$ & 341 & {$[4$} \\
\hline 2 & 2 & 4 & 2 & 2 & 2 & 2 & 4 5] & {$\left[\begin{array}{ll}4 & 5\end{array}\right]$} & 4 5] & {$\left[\begin{array}{ll}3 & 4\end{array}\right]$} & {$\left[\begin{array}{ll}2 & 3\end{array}\right]$} \\
\hline 3 & 3 & 4 & 1 & 1 & 1 & 1 & {$\left[\begin{array}{ll}2 & 3\end{array}\right]$} & {$\left[\begin{array}{lll}3 & 4\end{array}\right]$} & {$\left[\begin{array}{lll}2 & 3\end{array}\right]$} & {$\left[\begin{array}{lll}2 & 3\end{array}\right]$} & {$\left[\begin{array}{ll}4 & 5\end{array}\right]$} \\
\hline 4 & 3 & 4 & 2 & 3 & 3 & 1 & [4 4 5] & {$\left[\begin{array}{ll}4 & 5\end{array}\right]$} & [4 5] & {$\left[\begin{array}{ll}3 & 4\end{array}\right]$} & {$\left[\begin{array}{ll}3 & 4\end{array}\right]$} \\
\hline 5 & 2 & 4 & 2 & 1 & 2 & 1 & {$\left[\begin{array}{ll}3 & 4\end{array}\right]$} & {$\left[\begin{array}{lll}4 & 5\end{array}\right]$} & {$\left[\begin{array}{ll}3 & 4\end{array}\right]$} & {$\left[\begin{array}{ll}3 & 4\end{array}\right]$} & {$\left[\begin{array}{ll}4 & 5\end{array}\right]$} \\
\hline 6 & 3 & 3 & 1 & 1 & 2 & 1 & [3 4] & 3 4] & {$\left[\begin{array}{ll}3 & 4\end{array}\right]$} & {$\left[\begin{array}{ll}3 & 4\end{array}\right]$} & [4 5] \\
\hline 7 & 3 & 4 & 1 & 1 & 1 & 1 & {$\left[\begin{array}{ll}2 & 3\end{array}\right]$} & {$\left[\begin{array}{ll}3 & 4\end{array}\right]$} & {$\left[\begin{array}{ll}2 & 3\end{array}\right]$} & {$\left[\begin{array}{ll}3 & 4\end{array}\right]$} & {$\left[\begin{array}{ll}2 & 3\end{array}\right]$} \\
\hline 8 & 2 & 4 & 2 & 1 & 3 & 1 & {$\left[\begin{array}{ll}3 & 4\end{array}\right]$} & {$\left[\begin{array}{ll}4 & 5\end{array}\right]$} & [3 3 ] & [3 4 ] & {$\left[\begin{array}{ll}3 & 4\end{array}\right]$} \\
\hline 9 & 4 & 3 & 1 & 2 & 2 & 1 & {$\left[\begin{array}{ll}3 & 4\end{array}\right]$} & {$\left[\begin{array}{ll}3 & 4\end{array}\right]$} & [3 3 4] & {$\left[\begin{array}{ll}2 & 3\end{array}\right]$} & {$\left[\begin{array}{ll}2 & 3\end{array}\right]$} \\
\hline 10 & 3 & 3 & 1 & 1 & 1 & 1 & {$\left[\begin{array}{ll}2 & 3\end{array}\right]$} & {$\left[\begin{array}{ll}3 & 4\end{array}\right]$} & {$\left[\begin{array}{ll}2 & 3\end{array}\right]$} & [4 5] & {$\left[\begin{array}{ll}2 & 3\end{array}\right]$} \\
\hline 11 & 2 & 3 & 1 & 1 & 2 & 1 & {$\left[\begin{array}{ll}3 & 4\end{array}\right]$} & {$\left[\begin{array}{ll}3 & 4\end{array}\right]$} & {$\left[\begin{array}{ll}2 & 3\end{array}\right]$} & {$\left[\begin{array}{ll}3 & 4\end{array}\right]$} & [4 5] \\
\hline 12 & 1 & 3 & 2 & 2 & 2 & 1 & [4 5 5] & {$\left[\begin{array}{ll}4 & 5\end{array}\right]$} & [3 3 ] & {$\left[\begin{array}{ll}3 & 4\end{array}\right]$} & [4 5] \\
\hline 13 & 2 & 3 & 2 & 2 & 3 & 1 & [4 5 [ & {$\left[\begin{array}{ll}4 & 5\end{array}\right]$} & [4 4 5] & {$\left[\begin{array}{ll}3 & 4\end{array}\right]$} & {$\left[\begin{array}{ll}3 & 4\end{array}\right]$} \\
\hline 14 & 1 & 3 & 2 & 2 & 3 & 1 & {$\left[\begin{array}{ll}3 & 4\end{array}\right]$} & [4 5] & [3 4] & {$\left[\begin{array}{ll}3 & 4\end{array}\right]$} & {$\left[\begin{array}{ll}4 & 5\end{array}\right]$} \\
\hline 15 & 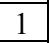 & 2 & 2 & 2 & 2 & 1 & [4 5] & [4 5] & {$\left[\begin{array}{ll}3 & 4\end{array}\right]$} & {$\left[\begin{array}{ll}3 & 4\end{array}\right]$} & [4 5] \\
\hline 16 & 1 & 2 & 1 & 1 & 3 & 1 & [ [ 4 5] & [4 5] & {$\left[\begin{array}{ll}3 & 4\end{array}\right]$} & {$\left[\begin{array}{ll}3 & 4\end{array}\right]$} & [4 5] \\
\hline 17 & 1 & 3 & 1 & 1 & 1 & 3 & [3 3 ] & {$\left[\begin{array}{ll}3 & 4\end{array}\right]$} & {$\left[\begin{array}{ll}2 & 3\end{array}\right]$} & [4 5] & {$\left[\begin{array}{ll}3 & 4\end{array}\right]$} \\
\hline 18 & 1 & 1 & 3 & 1 & 4 & 1 & {$\left[\begin{array}{ll}3 & 4\end{array}\right]$} & {$\left[\begin{array}{ll}3 & 4\end{array}\right]$} & {$\left[\begin{array}{ll}3 & 4\end{array}\right]$} & {$\left[\begin{array}{ll}4 & 5\end{array}\right]$} & {$\left[\begin{array}{ll}3 & 4\end{array}\right]$} \\
\hline 19 & 1 & 1 & 2 & 1 & 3 & 1 & {$\left[\begin{array}{ll}3 & 4\end{array}\right]$} & {$\left[\begin{array}{ll}3 & 4\end{array}\right]$} & {$\left[\begin{array}{ll}2 & 3\end{array}\right]$} & {$\left[\begin{array}{ll}3 & 4\end{array}\right]$} & {$\left[\begin{array}{ll}2 & 3\end{array}\right]$} \\
\hline 20 & 1 & 2 & 3 & 1 & 2 & 1 & {$\left[\begin{array}{ll}2 & 3\end{array}\right]$} & {$\left[\begin{array}{ll}3 & 4\end{array}\right]$} & {$\left[\begin{array}{ll}2 & 3\end{array}\right]$} & {$\left[\begin{array}{ll}2 & 3\end{array}\right]$} & {$\left[\begin{array}{ll}3 & 4\end{array}\right]$} \\
\hline
\end{tabular}

Table1. Information table for 20 randomly selected Tehran statistical units

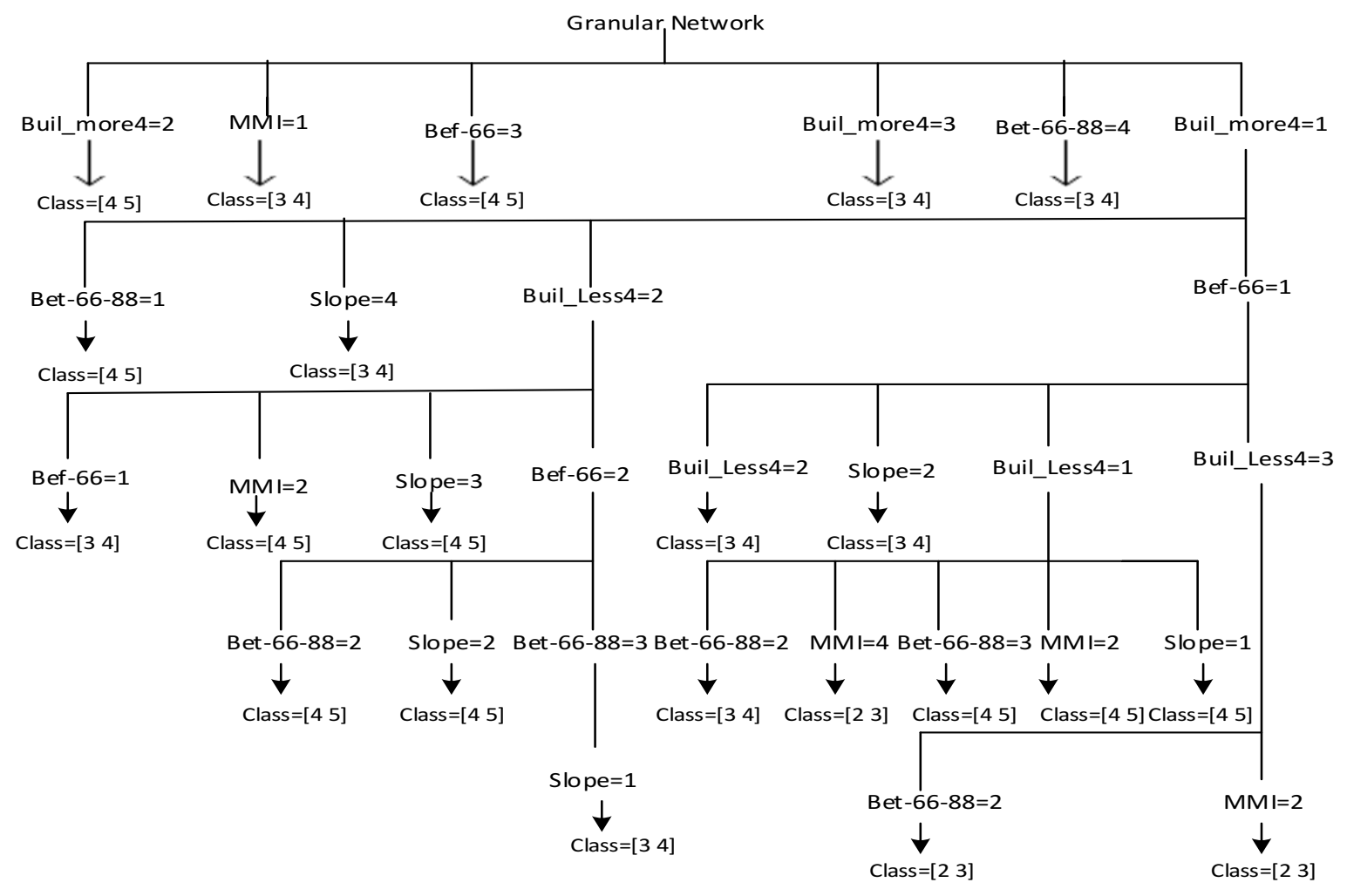

Figure 3. Granular Network 


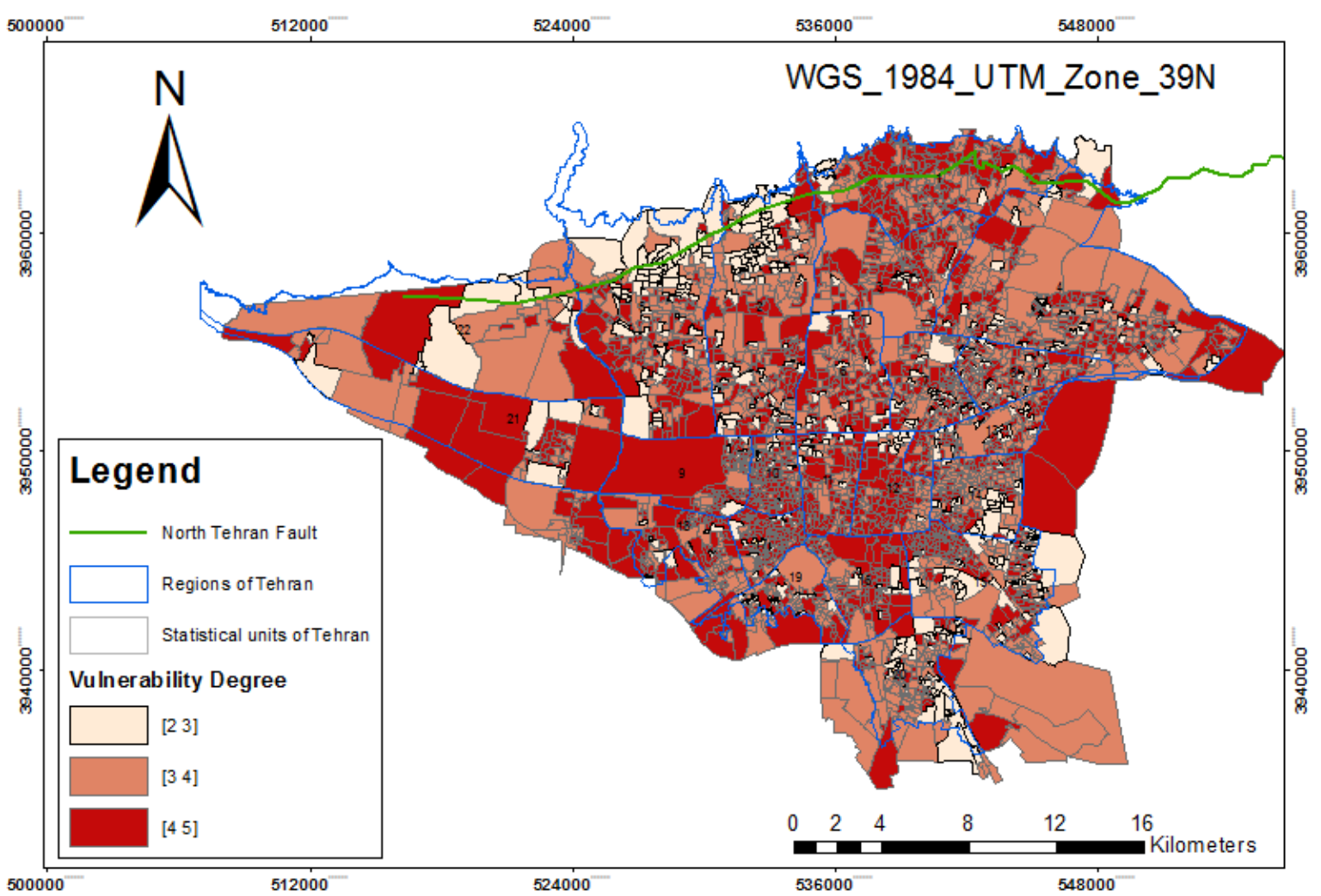

Figure 4. Tehran seismic physical vulnerability map using the integrated granular computing and interval Dempster-Shafer model 


\section{CONCLUSION}

Seismic physical vulnerability mapping, as a multi-criteria decision problem, is mainly associated with uncertainties of the experts' opinions as the decision classes. This paper has proposed a new approach to manage uncertainty and eliminate inconsistencies among the experts' opinions. In this research, interval computation and interval Dempster-Shafer were utilized to handle this type of uncertainty. Since the exact place, time and intensity of an earthquake is unpredictable, physical seismic vulnerability mapping with a low uncertainty is a useful method to assist reducing the impact of the vulnerability. Therefore, in order to help urban managers to plan and make informed decisions on earthquake disaster management at the right time, this paper has proposed a combination of granular computing and interval Dempster-Shafer approach with the purpose of producing Tehran seismic vulnerability map with minimum amount of uncertainty.

\section{REFERENCES}

Aghamohammadi, H., M. Mesgari, A. Mansourian and D. Molaei. 2013. Seismic human loss estimation for an earthquake disaster using neural network. International Journal of Environmental Science and Technology, Vol. 10, pp. 931-939.

Aghataher, R., M. Delavar and N. Kamalian. 2005. Weighing of contributing factors in vulnerability of cities against earthquakes. Map Asia Conference, Jakarta, Indonesia, Aug. 13 2005, pp. 22-25.

Amiri, A., M.R. Delavar, S. Zahrai and M. Malek. 2007. Tehran seismic vulnerability assessment using Dempster-Shafer theory of evidence, Proc. Map Asia Conference, Kuala Lumpur, Malaysia, Aug.14-16, 2007, 9p.

Amiri, A., M.R Delavar, S. Zahrai and M. Malek. 2008. Earthquake risk assessment in Tehran using Dominance-based rough set approach. Proc. The ISPRS Workshop on Geoinformation and Decision Support Systems, Tehran, Iran, Jan. 14 2008. pp. 13-26.

Berberian, M. and R. S. Yeats. 1999. Patterns of historical earthquake rupture in the Iranian Plateau. Bulletin of the Seismological Society of America 89(1), pp 120-139.

Dempster, A.P. 1968. A generalization of Bayesian inference. Journal of the Royal Statistical Society, Series $B$ 30,pp. 205-247.

Dou, Y., P. Zhang, J. Jiang, K. Yang and Y. Chen. 2014. MCDM based on reciprocal judgment matrix: a comparative study of E-VIKOR and E-TOPSIS algorithmic methods with interval numbers, Appl. Math, Vol. 8, pp. 1401-1411.

Gupta, M. M., R. K. Ragade and R. R. Yager. 1979. Advances in Fuzzy Set Theory and Applications, North-Holland Publishing Company. 770p.

Hashemi, M. and A. Alesheikh. 2012. Development and implementation of a GIS-based tool for spatial modeling of seismic vulnerability of Tehran, Natural Hazards and Earth System Sciences, Vol. 12, pp. 36-59.

JICA. 2000. The Study on Seismic Microzoning of the Greater Tehran Area in the Islamic Republic of Iran, Pacific Consultants International Report, OYO Cooperation, Japan.
Kang, B., Y. Zhang, X. Deng, J. Wu, X. Sun, and Y. Deng. 2011. Optimal aggregation of interval numbers based on genetic algorithm in group decision, Journal of Information and Computational Science, Vol. 8, pp.842-849.

Khamespanah, F., M.R. Delavar, and M.Zare. 2016. Uncertainty Management in Seismic Vulnerability Assessment Using Granular Computing Based on Neighborhood Systems, In: Uncertainty Modelling and Quality Control for Spatial Data, Edited by Shi, W. Wu, B. and Stein, A., CRC Press, Chapter 15, pp.255-267.

Lee, E. and Q. Zhu. 1992. An interval Dempster-Shafer approach, Computers \& Mathematics with Applications, Vol. 24, pp. 89-95.

Moore, R. E., R. B. Kearfott, and M. J. Cloud. 2009. Introduction to Interval Analysis: Siam.

Moradi, M., Delavar, M. R. and Moshiri, B. 2016. A GIS-based multi-criteria analysis model for earthquake vulnerability assessment using Choquet integral and game theory. Natural Hazards, 1-22.

Pawlak, Z. . 1982. Rough sets, International Journal of Parallel Programming, Vol. 11, pp. 341-356.

Pedrycz, W., A. Skowron and V. Kreinovich. 2008. Handbook of Granular Computing: John Wiley \& Sons.

Samadi Alinia, H. and M.R. Delavar.2011. Tehran's seismic vulnerability classification using granular computing approach, Applied Geomatics, Vol. 3, pp. 229-240.

Samadi Alinia, H., M.R. Delavar and Y. Yao. 2010. Support and confidence parameters to induct decision rules to classify Tehran's seismic vulnerability, Proc. The 6th International Symposium on Geo-Information for Disaster Management (Gi4DM 2010), Torino, Italy, Sept. 15, 2010, pp. 123-130.

Sentz, K. and S. Ferson. 2002. Combination of Evidence in Dempster-Shafer Theory, Vol. 4015: Citeseer.

Shafer, G. 1976. A Mathematical Theory of Evidence Vol .1: Princeton University Press Princeton.

Sheikhian, H., Delavar, M.R. and Stein, A., 2017, A GIS-based multi-criteria seismic vulnerability assessment using the integration of granular computing rule extraction and artificial neural networks, in Press, Transactions in GIS.

Silavi, T., M.R. Delavar, M. Malek, N. Kamalian and K. Karimizand. 2006. An integrated strategy for GIS-based fuzzy improved earthquake vulnerability assessment. ISPRS International Symposium on Geo-information for Disaster Management (Gi4DM), Goa, India, Sept. 25-26, 2006, 5p.

Wang, Y.-M, J.-B. Yang and D.-L. Xu. 2005. A two-stage logarithmic goal programming method for generating weights from interval comparison matrices, Fuzzy Sets and Systems, Vol. 152, pp. 475-498.

Wang, Y.-M. and T. M. Elhag. 2006. On the normalization of interval and fuzzy weights, Fuzzy Sets and Systems, Vol. 157, pp. 2456-2471. 
Yager, R. R. 1992. Decision making under Dempster-Shafer uncertainties, International Journal of General System 20:pp. $233-245$.

Yao, Y.Y.. 2001. On modeling data mining with granular computing, Proc. IEEE, The 25th Annual International Conference on Computer Software and Applications (COMPSAC 2001)., Chicago, U.S., Dec. 23, 2001, pp. 638643.

Yao, Y. and N. Zhong. 2002. Granular Computing Using Information Tables, In: Data Mining, Rough Sets and Granular Computing, ed: Springer, pp. 102-124.

Yao, J. .2007. A ten-year review of granular computing, IEEE International Conference on Granular Computing (GRC 2007), pp. 734-734.

Yao, Y. 2008. A Unified Framework of Granular Computing. Handbook of Granular Computing. W. Pedrycz, A. Skowron and V. Kreinovich (Eds), John Wiley \& Sons, pp. 401-410.

Zadeh, L. A. and J. Kacprzyk. 1999. Computing with Words in Information/Intelligent Systems 1: Foundations, Springer. 518p.

Zhao, Y. and Y. Yao. (2005). Interactive classification using a granule network, Proc. The Fourth IEEE Conference on Cognitive Informatics (ICCI 2005), Univ. of California Irvine, CA, USA, Aug. 8-10, pp. 250-259.

Zhong, N. , Y. Y. Yao, and M. Ohishima . 2003. Peculiarity oriented multidatabase mining, IEEE Transactions on Knowledge and Data Engineering, Vol. 15, pp. 952-960. 